\title{
Evaluation of a new work seat for industrial sewing operations
}

\author{
Results of three field studies
}

\author{
Chi-Yuang Yu and W. Monroe Keyserling \\ Center for Ergonomics, Department of Industrial and Operations Engineering, The University of Michigan, \\ Ann Arbor, Michigan, USA
}

A newly developed work seat for industrial sewing operations was compared with a traditional sewing work seat to evaluate the effectiveness of design features. The new seat was designed with special seat-pan and backrest features to accommodate the musculoskeletal geometry of a low sit-stand posture. The seat-pan consisted of a pelvic support which supported the ischial tuberosities and areas behind them, and a thigh support which maintained the thighs at a $15^{\circ}$ downward angle, resulting in a $105^{\circ}$ trunkthigh angle. The backrest consisted of a lumbar support which preserved lumbar lordosis and a thoracic support which supported the upper back during backward leaning. The traditional work seat was similar to an office chair ( $i$ e, a large horizontal seat-pan and a wide backrest) with the exception of having a higher than normal seat-height.

This investigation consisted of three studies to compare the seats: (1) A user comfort and acceptance experiment which compared the initial psychophysical responses of 50 industrial sewers when introduced to the new seat; (2) a backrest usage experiment which compared the duration of backrest use among 10 industrial sewers; and (3) a followup experiment to evaluate chair preference after extended use of the new seat. The results of the user comfort and acceptance experiment found that the new work seat had greater comfort and user preference; the results of the backrest usage experiment found that the new seat had greater backrest use than the traditional seat; the results of the follow-up experiment found that the preference for the new seat was maintained over time and not due to a Hawthorne Effect.

\section{Keywords: Seating, posture, industrial sewing}

\section{Introduction}

The advantage of using a chair for industrial sewing operations is that it can lower the expenditure of physical energy and eliminate or reduce body fatigue. On the other hand, it may also introduce excessive musculoskeletal stresses if the sitting posture is supported improperly (Mandall, 1976; Corlett and Eklund, 1984; Yu et al, in press).

Musculoskeletal stresses during sitting occur mainly in the lumbar region. It has been found that when a person moves from a standing posture $\left(180^{\circ}\right.$ trunk-thigh angle) to a normal sitting posture $\left(90^{\circ}\right.$ trunk-thigh angle), the pelvis rotates backward $28^{\circ}$ to $40^{\circ}$. The rotation of the pelvis, leading to the flattening of the lumbar spine, has been found to be approximately $25^{\circ}$ to $38^{\circ}$ (Akerblom, 1948; Schoberth, 1962; Andersson et al, 1979). The flattening of the lumbar curvature produces stresses on the lumbar discs, posterior ligaments and spinal nerves (Fig. 1).

When the lumbar spinal curvature is flattened, the compressive force on the lumbar discs increases approximately 35\% (Nachemson and Morris, 1964), and an asymmetrical force on the lumbar disc drives the nucleus posteriorly (Kapandji, 1974). Under chronic loading, the combination of these two forces may gradually distort, traumatise and prolapse the lamellae of the posterior annulus fibrosus (Hirsch and Schajowicz, 1953; Adams and Hutton, 1983a; 1985).

When flattening of the lumbar spinal curvature occurs, the posterior ligaments are stretched substantially (Kapandji, 1974), thereby increasing tension in these ligaments (Adams, et al, 1980; Panjabi et al, 1982). The tension may overstretch and traumatise these ligaments and tear the attachments to the spinal processes (Rissanen, 1960).

Finally, when the lumbar spine curvature is flattened, the tension on the lumbar spinal nerves increases due to a substantial increase in the length of the spinal canal (Breig, 1978). The tension may lead to tensile ischaemia and hamper the nutrition supply to the nerves, resulting in neurological dysfunction (Breig and Marions, 1963; Parke and Watanabe, 1985). The nerve tension may be increased further if that space is jeopardised by a lesion or prolapsed disc in the spinal canal (Breig, 1978). 


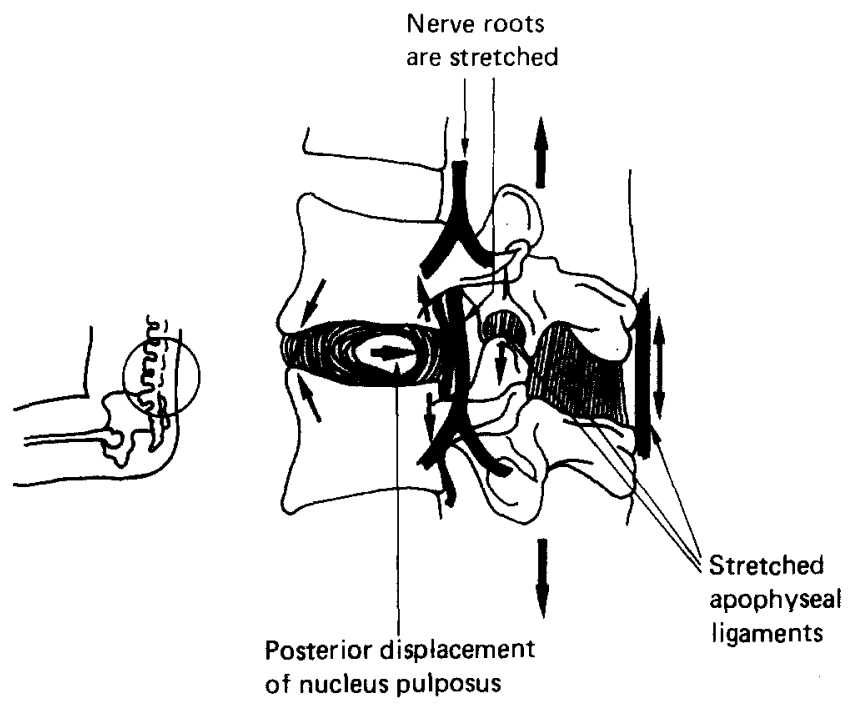

Fig. 1 Flattening of the lumbar spine introduces compression on the anterior side of disc, tension on the posterior side of disc and apophyseal joint ligaments, and tension on the spinal nerve roots

All these structures - the lumbar discs, the posterior ligaments and the lumbar nerves - are richly supplied with pain-sensitive nerve endings which are innervated when overstretched or traumatised (Yoshizawa et al, 1980). These may all be sources of low back pain.

Despite the fact that a seated posture may induce significant musculoskeletal stresses, these stresses can be lessened if a larger trunk-thigh angle is maintained. Keegan (1953) found that when the trunk-thigh angle is maintained at $135^{\circ}$, there is no significant backward rotation of the pelvis; therefore, the lumbar spine is in a neutral condition with minimal musculoskeletal stresses. This finding was confirmed by studies under zero-gravity conditions in space (Griffin, 1978). Based on these findings, it has been suggested that seated work be carried out using this posture if possible (Mandal, 1976; Engdahl, 1978).

However, due to the task and postural requirements of sewing operations, it is very difficult to maintain this recommended posture. Industrial sewing requires repetitive, co-ordinated use of the trunk and the upper and lower extremities. During sewing tasks, the trunk and upper extremities are used to manipulate fabric sections that may be large and/or heavy. The operator's right foot manipulates a pedal to control the machine speed while the right knee manipulates a control to raise and lower the needle 'foot'. If the seat-pan is sloped at too steep an angle, the operator will slide down the seat-pan and/or the left leg becomes fatigued from resisting the sliding tendency ( $\mathrm{Yu}$ et al, in press).

Although it is very difficult to maintain a $135^{\circ}$ trunk-thigh angle while sewing, seated postures with a trunk-thigh angle of greater than $90^{\circ}$ are commonly observed even on a traditional sewing chair (see Fig. 2). The traditional work chair is similar to an office chair except its seat-pan is generally adjusted 10 to $20 \mathrm{~cm}$ higher. Although the chair is able to maintain the worker with a trunk-thigh angle of greater than $90^{\circ}$, it does not support the posture properly. The problems associated with the traditional chair are caused by the size and shape of the seat-pan and backrest (Yu et al, in press).

The first problem with the traditional chair is that its horizontal seat-pan compresses the posterior aspect of the thighs and hinders the use of the backrest. The posterior aspect of the thighs is characterised by soft tissue and nerves which are not able to bear high pressure (Akerblom, 1954). In order to sit comfortably on the chair, establish a trunkthigh angle of more than $90^{\circ}$ and eliminate excessive pressure on the thighs, the worker has to slide forward to the front edge of the seat-pan. This move leaves the backrest too far back to be functional and the trunk remains unsupported during almost the entire work period. An unsupported trunk may result in forward slumping of the torso in order to minimise muscle activity (Kendall et al, 1967). This may be harmful because the slumped posture is stabilised by tension on the posterior annulus and apophyseal ligaments (Adams and Hutton, 1983b). In addition, when in the forward sitting position, there is no seat-pan support for the thighs.

The second problem with the traditional work chair is that its wide backrest interferes with the required trunk and upper extremity movements associated with reaching to the left, right or behind the body to obtain materials from temporary storage and to set aside finished items. The materials may be large and heavy, while the storage locations may be far away and high; therefore, extensive bending and twisting of the upper body and extremities are common. These movements are restricted by the wide backrest found in the traditional chairs. In order to eliminate backrest interference, the trunk must move forward (thus making the backrest ineffective) or the backrest must be removed from the seat.

Due to these problems, the musculoskeletal stresses associated with the traditional sewing work chairs may result in increased rates of back pain and disability. In a recent study of female sewing machine operators, $25 \%$ of the work population reported persistent back pain. None of these workers performed heavy lifting or other activities usually associated with elevated rates of back disorders (Keyserling et al, 1982).

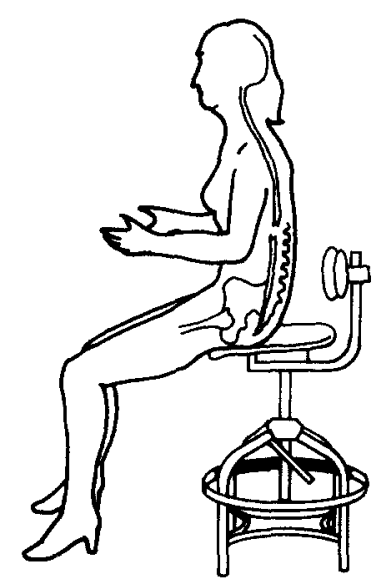

The traditional chair

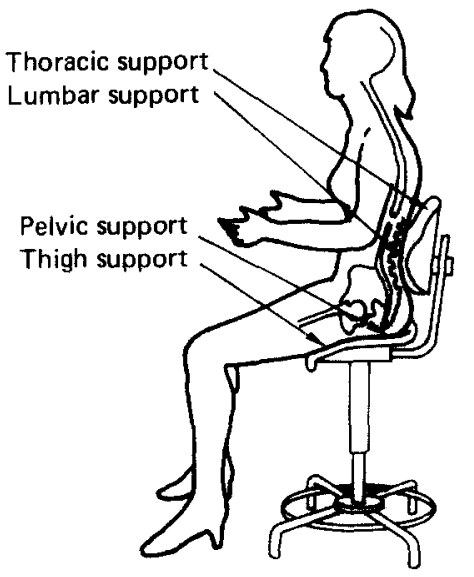

The new chair
Fig. 2 The traditional sewing work chair and the new sewing work chair 
A new chair was designed which matched selected features to the postural requirements of the sewing task. This chair was based on the findings of a previous study (Yu et al, in press), where the authors investigated the preferred sitting posture and chair design features for industrial sewing operations. The study used a highly adjustable pneumatic chair which allowed adjustment of seven parameters seat height, seat angle, seat angle rocking, seat swivel, backrest distance, backrest height and backrest angle. The results suggested that the preferred sitting posture was to maintain the trunk erect while keeping the thigh at $15^{\circ}$ angle below the horizontal, resulting in a $105^{\circ}$ trunk-thigh angle. The most significant design features were seat height and backrest distance. The seat height should be adjustable between $51 \mathrm{~cm}$ and $61 \mathrm{~cm}$ to allow workers of different heights to maintain the $105^{\circ}$ trunk-thigh angle while keeping their feet on the floor and pedal. The backrest distance should be adjustable between 10 and $15 \mathrm{~cm}$ measured horizontally and backward from the centre of the seat-pan (where the ischial tuberosities are located).

In addition, to support the sewing posture more effectively, the seat-pan and backrest were designed with special features. The seat-pan was contoured to produce a 'pelvic support' and a 'thigh support', while the backrest was shaped to produce a 'lumbar support' and a 'thoracic support' (see Fig. 2). The pelvic support was horizontal and short; it supported most of the upper body weight in an upward direction by providing a stable platform for the ischial tuberosities and areas behind them. (It has been shown that a total of $90 \mathrm{~cm}^{2}\left(14 \mathrm{in}^{2}\right)$ under the two ischial tuberosities is capable of supporting $50 \%$ of the total body weight (Swearingen et al, 1962). Therefore, the ischial tuberosities should be capable of supporting most of the weight of the upper body (Akerblom, 1948; Floyd and Roberts, 1958; Schoberth, 1962).) The thigh support followed the posterior contour of the thigh; it maintained the thighs at a $15^{\circ}$ angle below the horizontal and distributed the pressure from the front edge of the pelvic support over a larger area. The seat is padded with a $3 \mathrm{~cm}$ sponge foam. The lumbar support was located 13 to $19 \mathrm{~cm}$ behind the junction of the pelvic support and the thigh support (or 10 to $15 \mathrm{~cm}$ behind the ischial tuberosities) so that the backrest could be used more effectively during task performance. The thoracic support was extended upward and backward approximately to the level of the T7 spine segment. It could be used as an auxiliary support whenever the operator consciously leaned backward in an effort to extend the torso.

Furthermore, the width of the backrest was narrowed to only $20 \mathrm{~cm}$ ( 8 in) wide, just enough to support the central, posterior region of the trunk, but not enough to interfere with required torso and arm movements during task performance.

Based on this design, a large number of new chairs were manufactured for field testing in a factory that processes soft trim items (e g, seat covers) for the automotive industry. It was hypothesised that the new chair would be better than the traditional chair in allowing the worker to use the seatpan and backrest more effectively during task performance. Furthermore, it was hypothesised that these features would result in a higher level of user acceptance.

The principal purpose of this investigation was to compare the new and traditional chairs using user comfort, user acceptance and backrest usage as evaluation criteria. The user comfort and acceptance experiment evaluated the psycho- physical responses of a large number of subjects, while the backrest usage experiment evaluated the duration of backrest usage. In addition, a follow-up experiment to evaluate long-term chair preference was performed. The purpose of this study was to determine if the results of comfort and acceptance experiments were biased by a Hawthorne Effect.

\section{Methods}

\section{Experiment 1: User comfort and acceptance}

This experiment was performed one week after the new chairs were introduced to the participating plant.

\section{A. Experimental design}

1. Independent variables

a. Chair type: the new chair and the traditional chair.

b. Task type: Three types of tasks were defined based on the degree of body movement involved. The first task type was light sewing which involved sewing small pieces, such as tacking or joining. The second was medium sewing which involved joining medium-length pieces, such as welt cording. The third was heavy sewing which required joining large pieces, or previously sewed materials.

c. Subject's body height.

d. Subject's body weight.

\section{Dependent variables}

a. Overall body discomfort: Overall body discomfort was measured on an eight-point psychophysical rating scale $(0=$ no discomfort, $7=$ extreme discomfort) using an adaptation of the method developed by Corlett and Bishop (1976) and Wiker (1986).

b. Localised body discomfort: Fourteen body regions were evaluated (see Fig. 3). These ratings were also measured using an eight-point psychophysical rating scale.

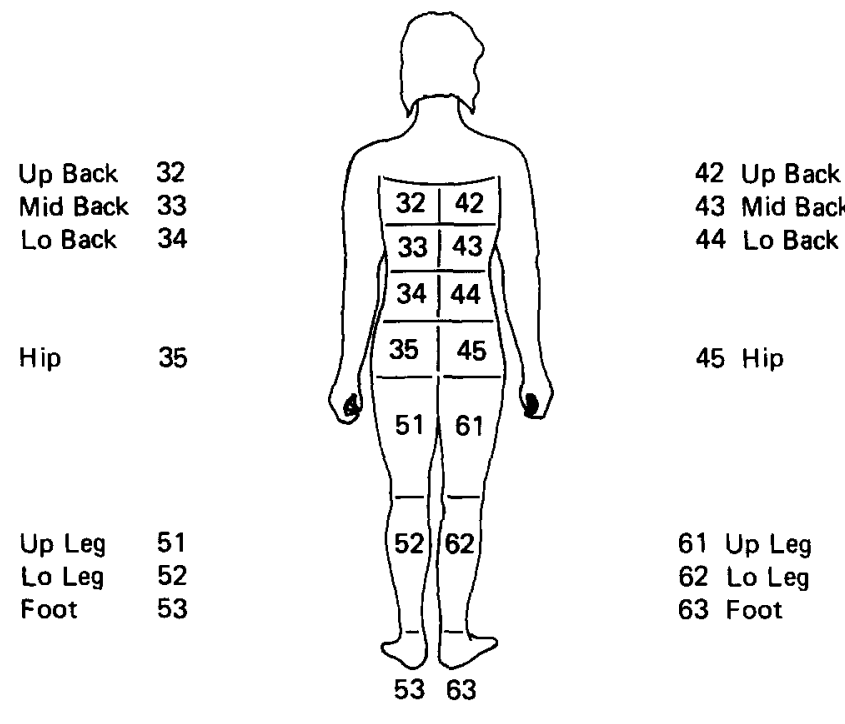

Body Regions (Back View)

Fig. 3 Fourteen regions of localised discomfort measurements (adapted from Corlett and Bishop, 1976; Wiker, 1986) 
c. Ease of adjustment: The subject was asked to rate the degree of difficulty in adjusting the chair to a desired configuration using an eight-point psychophysical scale.

d. General preference: The subject was asked to indicate preference through a binary choice between the new and the traditional chair.

\section{B. Subjects}

Fifty production sewing operators, 47 females and three males in an automotive trim plant, were recruited as subjects for this experiment. These subjects were, on the average, 42 years old with 13 years' experience, $163 \mathrm{~cm}$ in height, and $63 \mathrm{~kg}$ in weight. Among this group, six subjects had a history of lower back disorders. The subjects were compensated by the plant at their usual salary for the duration of this experiment.

\section{Apparatus}

1. Twenty-five new chairs: The seat was adjustable between $48 \mathrm{~cm}$ and $68 \mathrm{~cm}$. The pelvic support was $20 \mathrm{~cm}$ deep and $40 \mathrm{~cm}$ wide, the thigh support was $15 \mathrm{~cm}$ deep and $40 \mathrm{~cm}$ wide. It was padded with $3 \mathrm{~cm}$ sponge foam. The lumbar support was $15 \mathrm{~cm}$ high and $20 \mathrm{~cm}$ wide, the thoracic support was $15 \mathrm{~cm}$ high and $20 \mathrm{~cm}$ wide. The (centre of the) lumbar support was adjustable between $20 \mathrm{~cm}$ and $27 \mathrm{~cm}$ vertically above the seat-pan, and $13 \mathrm{~cm}$ to $20 \mathrm{~cm}$ horizontally behind the front edge of the pelvic support.

2. Twenty-five traditional chairs: The seat was adjustable between $43 \mathrm{~cm}$ and $60 \mathrm{~cm}$. The seat-pan was $35 \mathrm{~cm}$ deep and $40 \mathrm{~cm}$ wide, with a small ridge (1 cm high) in the front section. The backrest was $15 \mathrm{~cm}$ high and $35 \mathrm{~cm}$ wide, with a horizontal radius of $50 \mathrm{~cm}$. Its centre was adjustable between $23 \mathrm{~cm}$ to $30 \mathrm{~cm}$ above the rear edge of the seat. The chair was generally padded with $2 \mathrm{~cm}$ to $5 \mathrm{~cm}$ sponge foam.

3. Fifty sewing workstations: The workstation consisted of a sewing table and a stock table. The sewing table was $152 \mathrm{~cm}$ wide and $81 \mathrm{~cm}$ deep. The stock table was $121 \mathrm{~cm}$ wide and $121 \mathrm{~cm}$ deep, with a semicircular cut-out for the operator.

\section{Procedure}

Each subject evaluated the two types of chairs over four consecutive days. The subject used one type of chair every other day: 25 subjects used the new chair on 'odd days', and the traditional chair on 'even days'; the other 25 used the opposite sequence. Each day, after $4 \mathrm{~h}$ of normal sewing, the subject was asked to rate the four dependent variables on a questionnaire.

\section{E. Data analysis}

Overall body discomfort, localised body discomfort and ease of adjustment were analysed using multiple regression to evaluate the significance of the four independent variables on the dependent variable of interest (Neter et al, 1985). Among the four independent variables, chair type and task type were coded as indicator variables. Following the regression analysis, the Mann-Whitney Test was performed to compare mean rank differences due to the significant independent variables (Hollander and Wolfe, 1973).

General preference was analysed using the sign test to compare the difference in chair preferences. The sign for each subject was determined by the net response to the general preference question for the completed questionnaires (Note: Each subject responded to this question on four days. following the 4 -h trials.) If more questionnaires favoured the new chair, then a sign of ' + ' was assigned to the subject: conversely, if more questionnaires favoured the traditional chair, then a sign of '-' was assigned (Snedecor and Cochran, 1980). If tied, the subject was dropped (Wilkinson, 1985). Only the subjects with a ' $t$ ' or a '-' sign were analysed.

\section{Experiment 2: Backrest usage}

This experiment was performed three months after the new chairs were introduced to the study plant.

\section{A. Experimental design}

1. Independent variables

This experiment used the same four independent variables as Experiment 1.

\section{Dependent variable}

Duration of backrest use: The duration was defined as the total time in which the back applied a force greater than $1 \mathrm{~kg}$ on the backrest during a 30-min sampling period.

\section{B. Subjects}

Ten female sewing machine operators from the same automotive trim plant used for Experiment 1 were recruited for this experiment. These subjects were, on average, 45 years old with 14 years' experience, $160 \mathrm{~cm}$ in height, and $64 \mathrm{~kg}$ in weight. Among this group, two subjects had a history of lower back disorders. The participants were compensated at their regular wages.

\section{Apparatus}

1. New chairs: The new chair was equipped with a force transducer on the frame of the backrest.

2. Traditional chairs: The traditional chair was also equipped with a force transducer on the frame of the backrest.

3. Ten industrial sewing workstations.

4. Force monitor: This device was a strain gauge amplifier which received the output signal from the force transducer on the backrest and amplified the signal for input to a personal computer.

5. Compaq computer: This computer was equipped with an analogue-to-digital converter to produce digital force output. The computer was programmed to integrate the total time during the 30 -min session where pressure on the backrest exceeded $1 \mathrm{~kg}$.

\section{Procedure}

This experiment lasted four days. Each day, the subjects used the instrumented chair for a 30 -min sewing period for data acquisition. As in Experiment 1, the subject used one type of chair every other day: five subjects used the new chair on 'odd' days, and the traditional chair on 'even' days; the other five used the opposite sequence. During the data acquisition period, the subject was asked to perform regular sewing operations for $30 \mathrm{~min}$, and the duration of backrest use was sampled. 


\section{E. Data analysis}

Duration of backrest use was analysed using multiple regression to evaluate the significance of the four independent variables on the dependent variable of interest (Neter et al, 1985). Among the four independent variables, chair type and task type were coded as indicator variables. Following the regression analysis, the Student $t$-test was performed to compare mean differences due to the significant independent variables.

\section{Experiment 3: Follow-up study}

This experiment was performed to evaluate long-term user acceptance of the new chair following six months of regular use.

\section{A. Experimental design}

1. Independent variable: Chair type

2. Dependent variable: General preference

\section{B. Subjects}

Sixty-two production sewing operators in three production units, 60 females and two males, were recruited for this experiment. These subjects were, on average, 43 years old with 13 years' experience, $162 \mathrm{~cm}$ in height, and $62 \mathrm{~kg}$ in weight. Among this group, five subjects had a history of lower back disorders. The participants were compensated at their regular wages.

\section{Apparatus}

Sixty-two sewing workstations: Each workstation used the preferred work chair which had been chosen by the operator.

\section{Procedure}

This experiment was performed during a regular production period. Each subject was asked to circle the preferred chair on a binary choice between the new and the traditional chair.

\section{E. Data analysis}

General preference was analysed using the sign test (Snedecor and Cochran, 1980). If the preferred chair was not indicated or both chairs were circled, the subject was dropped and not analysed.

\section{Results}

\section{Experiment 1: User acceptance}

Though 50 subjects agreed to participate in this experiment, 27 withdrew on or after the second day for various reasons (see the Discussion section below for additional information). The results presented in this section are principally derived from the group of 23 subjects who completed the entire four-day experiment. In addition, a general preference test based on responses from all 50 subjects is presented. (Note: All 50 subjects completed at least the first day of the experiment.)

\section{Overall body discomfort}

The result of the regression analysis showed that chair type was the only significant variable $(F=30.86, P<0.01$, see Table 1). The result of the Mann-Whitney Test showed that the mean rank of overall body discomfort when sitting on the new chair was 33.03 , which was significantly $(Z$-cor $=4.89, P<0.01)$ lower than when sitting on the traditional chair (mean rank $=59 \cdot 96$ ). This result suggests that the new chair was more comfortable than the traditional chair. Overall body discomfort ratings of both the new chair and the traditional chair are presented in Fig. 4.

\section{Localised body discomfort}

Localised body discomfort on each of 14 regions was independently analysed. The results of the regression analysis showed that chair type was the only significant variable in 12 regions (see Table 1). The results of the MannWhitney Test showed that the mean rank of each region when sitting on the new chair was significantly lower than the corresponding rating when sitting on the traditional chair (see Table 2). This result suggests that the new chair was more comfortable than the traditional chair.

\section{Ease of adjustment}

The result of the regression analysis showed that no independent variable was found to be significantly related to this variable (see Table 1).

\section{General preference}

The analysis of general preference was performed on two samples - one was the 23 subjects who completed the whole experiment, the other was the 50 subjects who completed at least the first day of the experiment.

In the group of 23 subjects, 19 subjects preferred the new chair, three preferred the traditional chair and one showed no preference. The no-preference subject was dropped and not analysed. The sign test analysis showed that preference for the new chair was significantly greater than preference for the traditional chair $(Z c=3 \cdot 19, P<0.01$, see Table 3$)$.

In the group of 50 subjects, 41 subjects preferred the new chair, six preferred the traditional chair and three showed no preference. The sign test analysis showed that preference for the new chair was significantly greater than preference for the traditional chair $\left(Z_{c}=4.95, P<0.01\right.$, see Table 3$)$.

\section{Experiment 2: Backrest usage}

The result of the regression analysis of backrest use showed that chair type was the only significant independent variable $(F=54.59, P<0.01$, see Table 1$)$. The results of the corresponding $t$-test showed that the mean total time of backrest use when sitting on the new chair was $20.52 \mathrm{~min}$ or $68.40 \%$ which was significantly $(t=6.24, P<0.01)$ higher than when sitting on the traditional chair, $3.82 \mathrm{~min}$ or $12.76 \%$. This finding suggests that the backrest of the new chair was more effective than that of the traditional chair.

\section{Experiment 3: Follow-up study}

Out of a total of 62 subjects, 48 subjects preferred the new chair, 12 preferred the traditional chair and two showed no preference. The sign test analysis showed that preference for the new chair was significantly greater than preference for the traditional chair $(Z c=4.51, P<0.01$, see Table 3$)$. The results suggested that the new chair was still preferred to the traditional chair. 
Analyses of overall discomfort

( $n=23$ subjects $\times 2$ trials in each chair)

\begin{tabular}{|c|c|c|c|c|c|c|c|}
\hline \multicolumn{2}{|c|}{ Chair type } & \multicolumn{2}{|c|}{ Task type } & \multicolumn{2}{|c|}{ Subject's height } & \multicolumn{2}{|c|}{ Subject's weight } \\
\hline F-stat & $\mathbf{p}$ & F-stat & $p$ & F-stat & $p$ & $\overline{F-s t a t}$ & $\mathbf{p}$ \\
\hline $30 \cdot 86$ & $<0.01$ & 0.03 & ns & 0.01 & ns & 0.02 & ns \\
\hline
\end{tabular}

ns: Indicates $P>0.05$

Analyses of localised discomfort

( $n=23$ subjects $\times 2$ trials in each chair)

\begin{tabular}{|c|c|c|c|c|c|c|c|c|}
\hline \multirow[b]{2}{*}{ Region } & \multicolumn{2}{|c|}{ Chair type } & \multicolumn{2}{|c|}{ Task type } & \multicolumn{2}{|c|}{ Subject's height } & \multicolumn{2}{|c|}{ Subject's weight } \\
\hline & F-stat & $\mathbf{p}$ & F-stat & $\mathbf{p}$ & F-stat & $\mathbf{p}$ & F-stat & $\mathbf{p}$ \\
\hline 32 & $13 \cdot 98$ & $<0.01$ & $2 \cdot 22$ & $\mathrm{~ns}$ & 0.00 & ns & 0.11 & ns \\
\hline 33 & $12 \cdot 02$ & $<0.01$ & 0.06 & $\mathrm{~ns}$ & 0.01 & ns & 0.31 & ns \\
\hline 34 & $17 \cdot 93$ & $<0.01$ & 0.51 & $\mathrm{~ns}$ & 0.37 & ns & 0.50 & ns \\
\hline 35 & $25 \cdot 03$ & $<0.01$ & $1 \cdot 04$ & $\mathrm{~ns}$ & $3 \cdot 16$ & ns & 0.21 & ns \\
\hline 42 & $15 \cdot 84$ & $<0.01$ & 0.26 & ns & 0.31 & ns & 0.21 & ns \\
\hline 43 & $18 \cdot 27$ & $<0.01$ & 0.49 & $\mathrm{~ns}$ & 0.37 & ns & 0.16 & ns \\
\hline 44 & $24 \cdot 60$ & $<0.01$ & 0.81 & ns & $0 \cdot 48$ & ns & 0.22 & ns \\
\hline 45 & $26 \cdot 10$ & $<0.01$ & $1 \cdot 17$ & $\mathrm{~ns}$ & $3 \cdot 15$ & ns & 0.00 & ns \\
\hline 51 & $9 \cdot 68$ & $<0.01$ & 0.51 & $\mathrm{~ns}$ & $1 \cdot 08$ & ns & $2 \cdot 85$ & ns \\
\hline 52 & $4 \cdot 08$ & $<0.05$ & 0.01 & ns & 0.01 & ns & $2 \cdot 98$ & ns \\
\hline 53 & $1 \cdot 41$ & ns & $0 \cdot 30$ & $\mathrm{~ns}$ & 0.14 & ns & $7 \cdot 76$ & $<0.01$ \\
\hline 61 & $9 \cdot 82$ & $<0.01$ & 0.58 & ns & $1 \cdot 12$ & ns & $2 \cdot 95$ & ns \\
\hline 62 & $4 \cdot 47$ & $<0.05$ & 0.58 & $\mathrm{~ns}$ & 0.29 & ns & $2 \cdot 90$ & ns \\
\hline 63 & $2 \cdot 31$ & ns & 0.42 & ns & $1 \cdot 04$ & ns & $7 \cdot 09$ & $<0.01$ \\
\hline
\end{tabular}

ns: Indicates $P>0.05$

Analyses of ease of adjustment

( $n=23$ subjects $\times 2$ trials in each chair)

\begin{tabular}{|c|c|c|c|c|c|c|c|}
\hline \multicolumn{2}{|c|}{ Chair type } & \multicolumn{2}{|c|}{ Task type } & \multicolumn{2}{|c|}{ Subject's height } & \multicolumn{2}{|c|}{ Subject's weight } \\
\hline F-stat & $\mathbf{p}$ & F-stat & $p$ & F-stat & $\mathbf{p}$ & F-stat & $\mathbf{p}$ \\
\hline 0.96 & $\mathrm{~ns}$ & $1 \cdot 18$ & ns & 0.45 & ns & 0.46 & ns \\
\hline
\end{tabular}

ns: Indicates $P>0.05$

Analyses of backrest use

( $n=10$ subjects $\times 2$ trials in each chair)

\begin{tabular}{|c|c|c|c|c|c|c|c|}
\hline \multicolumn{2}{|c|}{ Chair type } & \multicolumn{2}{|c|}{ Task type } & \multicolumn{2}{|c|}{ Subject's height } & \multicolumn{2}{|c|}{ Subject's weight } \\
\hline F-stat & $\mathbf{p}$ & F-stat & $\mathbf{p}$ & F-stat & $p$ & F-stat & $\mathbf{p}$ \\
\hline 54.59 & $<0.01$ & $2 \cdot 74$ & ns & 1.97 & ns & $1 \cdot 01$ & ns \\
\hline
\end{tabular}

ns: Indicates $P>0.05$

\section{Discussion}

There were several reasons why 27 subjects failed to complete Experiment 1. First, each subject had already determined his/her chair preference by the second day of the experiment. As a result, these participants felt that sitting on the less-preferred chair for four hours on additional days was unacceptable. Second, there was no incentive (i e, payment or bonus) for continued participation, the level of co-operation was determined by subjects' tolerance toward the inconvenience caused by this study. For instance, the study required that participants who usually work at multiple 


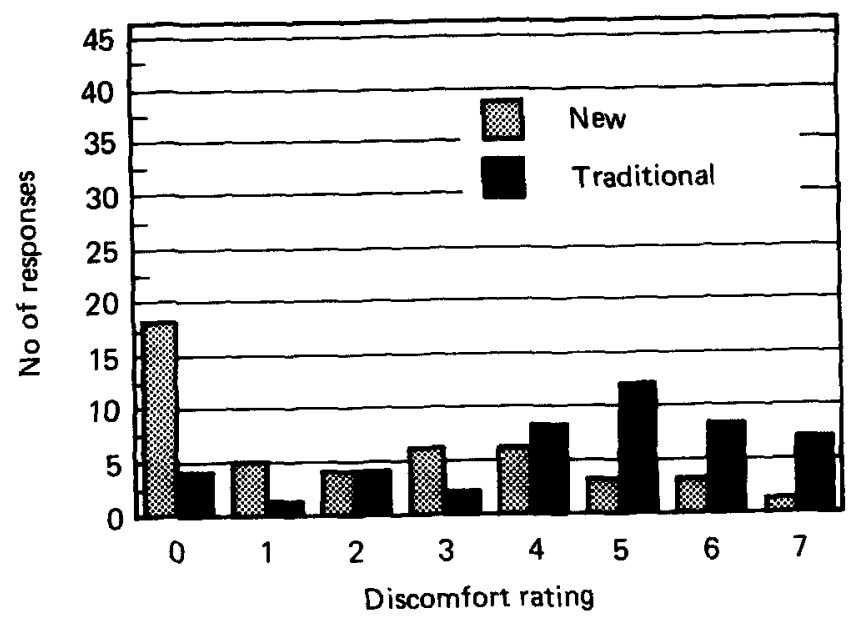

Fig. 4 Results of overall body discomfort, new vs traditional sewing chairs

Table 2: Mean rank difference in comfort due to chair type for the 12 significant body regions

Analyses of localised discomfort ( $n=23$ subjects $\times 2$ trials in each chair)

\begin{tabular}{ccccc}
\hline \multicolumn{5}{c}{ Mean rank } \\
\cline { 2 - 4 } Region & $\begin{array}{l}\text { New } \\
\text { chair }\end{array}$ & $\begin{array}{c}\text { Traditional } \\
\text { chair }\end{array}$ & Z-cor & p \\
\hline 32 & 37.85 & 55.14 & 3.29 & $<0.01$ \\
33 & 38.09 & 54.90 & 3.20 & $<0.01$ \\
34 & 36.43 & 56.56 & 3.73 & $<0.01$ \\
35 & 35.57 & 57.42 & 4.13 & $<0.01$ \\
42 & 37.16 & 55.83 & 3.54 & $<0.01$ \\
43 & 36.07 & 56.92 & 3.93 & $<0.01$ \\
44 & 34.78 & 58.21 & 4.34 & $<0.01$ \\
45 & 35.45 & 57.54 & 4.17 & $<0.01$ \\
51 & 39.53 & 53.46 & 2.66 & $<0.01$ \\
52 & 42.04 & 50.95 & 1.74 & $<0.05$ \\
61 & 39.48 & 53.51 & 2.68 & $<0.01$ \\
62 & 41.52 & 51.47 & 1.94 & $<0.05$ \\
\hline
\end{tabular}

workstations remain at the same workstation for four hours. This required subjects to move an unusually large amount of stock. Third, other reasons, such as medical problems or absenteeism, prevented a few subjects from completing the experiment.

At the completion of Experiment 1, the 27 subjects were interviewed to determine their reasons for withdrawal. The interviews revealed that 19 subjects did not want to use the old chairs, while three subjects would not use the new chairs. Among these three subjects who disliked the new chairs, two had undergone low-back surgery in the past and the other was too short to sit comfortably on the new chair. Since the low-back patients had been instructed by their doctors to carefully monitor their trunk postures, they were reluctant to try the new chairs. The short individual was only $150 \mathrm{~cm}$ tall and could only sit on the front edge (i e, the thigh support) of the new seat. Because the thigh support is slanted downward, this tended to push her forward causing her to slide off the seat.

The user preference results of this study are believed to be due to the difference between chairs rather than to a Hawthorne Effect. The Hawthorne Effect (a phenomenon in which a person works harder or feels better when participating in something new or special) can be a major confounder in studies which compare a new condition with an old condition (Chapanis, 1959). Experiment 1 was performed only one week after the new sewing chairs were introduced to the plant. In order to evaluate whether the findings of Experiment 1 were possibly biased by a Hawthorne Effect, Experiment 2 was performed after a threemonth delay and Experiment 3 was performed after a sixmonth delay. The results of all three studies were similar. Experiments 1 and 3 showed that users demonstrated a strong preference for the new chair when given a binary choice. Experiment 2, which utilised objective rather than psychophysical measures, showed greater utilisation of the backrest use when using the new chair. These findings collectively indicate the superiority of the new chair and discount the likelihood of a Hawthorne bias.

The primary reason for preferring the new seat was that the new seat-pan provided stable postural support without causing adverse effects. Many of the sit-stand chairs that had been previously proposed and investigated were effective in preserving the lumbar lordosis, but none had been fully accepted in industrial settings. For example, Mandal (1976) and Engdahl (1978) proposed a sit-stand posture with a forward-slanted seat-pan, which was very

Table 3: Results of general preference

\begin{tabular}{llllll}
\hline \multirow{2}{*}{ Sample size } & \multicolumn{2}{c}{ Chair preference } & Tied & Zc-statistic & Significance \\
\cline { 2 - 5 } & New & Traditonal & & & \\
\hline 23-subject & 19 & Results of Study 1 & & \\
\hline 50-subject & 41 & 3 & 1 & 3.192 & $<0.01$ \\
\hline 62-subject & 6 & 3 & 4.959 & $<0.01$ \\
\hline
\end{tabular}


effective in preventing the backward rotation of the pelvis and preserving a better lumbar lordosis. However, this seat used a forward-slanted seat-pan which was somewhat unstable and tended to produce a horizontal shear force that affected the soft tissue of the buttocks, and introduced more load at the feet (Corlett and Eklund, 1984). Mandal (1976) also proposed a horse-riding posture which Bendix et al (1985) tested using a saddle-shaped seat. This seat was stable in supporting the sitter and maintained lumbar lordosis, but it proved difficult for some users to get on and off (Bendix et al, 1985; Corlett and Eklund, 1984). Congleton (1983) developed a highly-contoured seat which almost wrapped around the buttocks and thighs. Although the seat was very stable, it was also less convenient to get on and off, or to move around in freely when seated. The new seat-pan investigated in this study, on the other hand, provided stable support for the upper body, while at the same time causing neither horizontal shear force on the buttocks, nor problems of mobility or accessibility.

The second reason for preferring the new seat was that the backrest was very effective in supporting the back during task performance. The new seat-pan supports a sit-stand posture with $105^{\circ}$ trunk-thigh angle. In this posture, the pelvis was still at a slightly rotated position and the lumbar spine was still somewhat flattened. Therefore the backrest was functional, because it stopped the back from slumping and produced a more lordotic lumbar spinal curvature.

Although the results of this investigation showed that the new chair was better than the traditional chair both in psychophysical response and objective measurements, there were still some complaints about the seat-pan design. The new seats were designed based on fitting trials on a small group of college students because many of the required measurements were not available in the existing anthropometric databases. Therefore some subjects, mostly the short ones, complained that they slid forward due to the need to sit on the thigh support, or that they could not use the backrest effectively. These complaints appear to be related to mismatch between the dimensions of the seat and the body. To eliminate these complaints, additional anthropometric and biomechanical studies are recommended to refine this new design.

The relationship between sitting height and work surface height was not considered in this research. The low sit-stand posture investigated was normalised to maintain the thigh $15^{\circ}$ below the horizontal while keeping the subject's feet in contact with the floor and foot pedal. As a result, the seat height was set by the popliteal height and the femur length of the user. Thus, small individuals found that the seat was too low in relation to the work surface height, while large individuals found that it was too high. Therefore, it was observed that the small persons adjusted the seat height higher than the normalised seat height and used a trunk-thigh angle greater than $105^{\circ}$. In contrast, the large persons adjusted the seat lower than the normalised seat height, resulting in a smaller trunk-thigh included angle. In order to minimise this problem, a further study investigating the relationship between sitting height and work surface height is recommended.

\section{Conclusions}

The results of this study suggest that the new seat-pan and backrest design appear to be appropriate for a low sit-stand posture during industrial sewing. The seat-pan, consisting of a pelvic support and a thigh support, supports the upperbody weight in an upright direction, maintains $105^{\circ}$ trunkthigh angle, but does not produce a horizontal shear force on the buttocks. The backrest, consisting of a lumbar support and a thoracic support, stabilises the back both in erect sitting and backward leaning. Its small width provides enough support for the upper and lower back, but does not interfere with required arm movements during task performance.

The results of this study suggest a slightly more acute trunk-thigh angle $\left(105^{\circ}\right)$ than recommended in previous studies of sit-stand chairs. This difference may be due to specific tasks requirements ( $\mathrm{g}, \mathrm{co}$-ordination of hand, body and foot motions) associated with production sewing.

\section{Acknowledgements}

This research was supported by research contracts provided by the Ford Motor Company Body and Assembly Operations, and the Ford Chesterfield Trim Plant. The authors wish to thank Mr William Brooks, Mr Richard Pennoni, and Ms Chris Lenihan for their support. The authors also wish to thank Mr James Foulke for his assistance.

\section{References}

Adams, M.A., Hutton, W.C., and Scott, J.R.R. 1980, Spine, $5,245-253$. The resistance to flexion of the lumbar intervertebral joint.

Adams, M.A., and Hutton, W.C. 1983(a), J Bone Joint Surgery, 65B, 2, 199-203. The effect of fatigue on the lumbar intervertebral disc.

Adams, M.A., and Hutton, W.C. 1983(b), Spine, 8,3, $327-330$. The mechanical function of the lumbar apophyseal joints.

Adams, M.A., and Hutton, W.C. 1985, J Bone Joint Surgery 67B,4, 625-629. The effect of posture on the lumbar spine.

Akerblom, B. 1948, Standing and sitting posture, with special reference to the construction of chairs. Doctoral dissertation. Nordiska Bokhandeln, Stockholm.

Akerblom, B. 1954 , Symposium on human factors in equipment design, (Floyd and Welford, Eds) Chair and sitting. H.H. Lewis \& Co, London.

Andersson, G.B.J., Murphy, R.W., Ortengren, R., and Nachemson, A.L. 1979, Spine, 4,1, 52-58. The influence of backrest inclination and lumbar support on lumbar lordosis.

Bendix, T., Krohn, L., Jessen, L., and Aaras, A. 1985, Spine 10,433-439. Trunk posture and trapezius muscle load while working in standing, support standing, and sitting positions.

Breig, A., and Marions, O. 1963, Acta Radiology, Vol 1. Diagnosis, pp 1141-1160. Biomechanics of the lumbosacral nerve roots.

Breig, A. 1978, Adverse mechanical tension in the central nervous system, John Wiley \& Sons, New York.

Chapanis, A. 1959, Research techniques in human engineering. The Johns Hopkins Press, Baltimore.

Congleton, J.J. 1983, Design and evaluation of a neutral posture chair, unpublished doctoral dissertation, Texas Tech University, College Station, Texas.

Corlett, E.N., and Bishop, R.P. 1976, Ergonomics, 19,2, 175-182. A technique for assessing posture discomfort.

Corlett, E.N., and Eklund, J.A.E. 1984, A ppl Ergonomics, $15,2,111-114$. How does a backrest work? 
Engdahl, S. 1978, Sitting work posture, (B. Jonsson, Ed) National Board of Occupational Safety and Health (Sweden), No 12 . Specification for office furniture.

Floyd, W.F., and Roberts, D.F, 1958, Anatomical physiological and anthropometric principles in the design of office chairs and tables, (BS 3034:1958) British Standards Institution, London.

Griffin, B.N. 1978, The influence of zero-G and acceleration on the human factors of spacecraft design, NASA Space Center.

Hirsch, C., and Schajowicz, F. 1953, A cta Orthopaedica Scand, 22, 184-231. Studies on structural changes in the lumbar annulus fibrous.

Hollander, M., and Wolfe, D.A. 1973, Nonparametric statistical methods. John Wiley and Sons, New York.

Kapandji, I,A. 1974, The physiology of joints, Vol 3, Churchill Livingston, London and Edinburgh.

Keegan, J.J. 1953, J Bone \& Joint Surgery, 35A, 589-603. Alterations of the lumbar curve related to posture and sitting.

Kendall, H.O., Kendall, F.P., and Boynton, D.A. 1967 , Posture and pain, Robert E. Krieger Publishing Co Inc, Malabar, Florida.

Keyserling, W.M., Donoghue, J.L., Miller, A.B., and Punnet, L. 1982, Repetitive trauma disorders in the garment industry, Technical report: NIOSH contract No PO 81-3220 (Department of the Environment Health Science, Harvard School of Public Health, Boston, MA).

Mandal, A.C. 1976, Appl Ergonomics, 12,1, 19-26. The seated man (homo sedens), the seated work position, theory and practice.

Nachemson, A., and Morris, J.B. 1964, J Bone \& Joint Surgery, 46(a), 1077. In vivo measurements of intradiscal pressure, discometry, a method for determination of pressure in the lumbar discs.
Neter, J., Wasserman, W., and Kutner, M.H. 1985, Applied linear statistical models. Richard D. Irwin, Inc, Homewood, Illinois.

Panjabi, M.M., Goel, V.K., and Takata, K. 1982, Spine, 7,3, 192-203. Physiological strains in the lumbar spinal ligaments, and in vivo biomechanical study.

Parke, W.W., and Watanabe, R. 1985, Spine, 10,6, 508-515. The intrinsic vasculature of the lumbosacral spinal nerve roots.

Rissanen, P.M. 1960, A cta Orthop Scans (Suppl) 44. The surgical anatomy and pathology of the supraspinous and interspinous ligaments of the lumbar spine with special reference to ligament rupture.

Schoberth, V.H. 1962, Sitzhatung, Sitzschaden, Sitzmobel. Spinger, Berlin.

Schoberth, V.H. 1969 , Sitting posture, (E. Grandjean, Ed) Taylor and Francis, London, pp 98-111. Die wirbelsaule von schulkindern - orthopadische forderungen an schulsitze.

Snedecor, G.W., and Cochran, W.G. 1980, Statistical methods The Iowa State University Press, Ames, Iowa.

Swearingen, J.J., Wheelwright, C.D., and Garner, J.D. 1962, An analysis of sitting areas and pressure of man, Report No 62-1, US Civil Aero-Medical Research Institute, Oklahoma City.

Wiker, S.F. 1986, Effects of relative hand location upon movement time and fatigue. The University of Michigan, Ann Arbor, Michigan, unpublished doctoral dissertation.

Wilkinson, L. 1985, Systat: The system for statistics. Systat Inc, Evanston, Il.

Yoshizawa, H., O'Brien, J.P., Simith, W.T., and Trumper. $1980, J$ Pathology. The neuropathology of intervertebral discs removed for low back pain.

Yu, C.Y., Keyserling, W.M., and Chaffin, D.B. (In press). Ergonomics. Development of a work seat for industrial sewing operations: results of a laboratory study. 